\title{
Selection of internal control genes for real-time quantitative RT-PCR assays in the oomycete plant pathogen Phytophthora parasitica
}

\author{
Hao-Zhi Yan, Ruey-Fen Liou * \\ Department of Plant Pathology and Microbiology, National Taiwan University, Taipei 106, Taiwan \\ Received 14 October 2005; accepted 27 January 2006 \\ Available online 13 March 2006
}

\begin{abstract}
Real-time quantitative reverse transcription-PCR (qRT-PCR) has become one of the most commonly used methods for RNA quantification in recent years. To obtain reliable results with biological significance, it is important that qRT-PCR data are normalized with a proper internal control. In this study, 18 housekeeping genes were selected and evaluated for their potential as a suitable internal control for study of gene expression in the oomycete plant pathogen Phytophthora parasitica. Analysis of qRT-PCR data using the geNorm software indicated that, although commonly used as internal controls, $\beta$-actin (ACT) and translation elongation factor $1 \alpha$ (eEF1A) might not be the best choice due to variable expression across different life stages of $P$. parasitica. Instead, other genes would serve as better controls, including ubiquitin-conjugating enzyme (Ubc), WS21, and $\beta$-tubulin (Tub-b) for 'asexual stage,' Ubc and Tub-b for 'sexual reproduction,' while Ubc and WS21 for the stage of pathogenesis, because of their constant expression levels in each given subset of RNA samples. Although normalization with more than one gene would generate more reliable results, use of a single stably expressed gene as an internal control would suffice for accurate data normalization in some experiments.
\end{abstract}

(C) 2006 Elsevier Inc. All rights reserved.

Keywords: $\beta$-tubulin; Housekeeping gene; Internal control; Normalization; Phytophthora parasitica; Quantitative RT-PCR; Ubc; WS21

\section{Introduction}

Phytophthora represent a large group of devastating oomycete pathogens, which cause important diseases in a wide variety of plant species, including potato, tomato, soybean, and valuable forest trees (Erwin and Ribeiro, 1996). Although similar to fungi in morphology and growth patterns, analyses based on sequence comparisons indicated that Oomycetes, now part of Stramenopiles, are phylogenetically distinct from true fungi (Baldauf et al., 2000; Gunderson et al., 1987). Phytophthora are diploid for the majority of their life cycle: mycelia, sporangia, zoospores, and cysts, which represent the asexual stage. Haploid exists only briefly in antheridia and oogonia prior to fertilization, which requires interaction between $\mathrm{A} 1$ and $\mathrm{A} 2$ mating

\footnotetext{
* Corresponding author. Fax: +88622362 0271.

E-mail address: rfliou@ntu.edu.tw (R.-F. Liou).
}

types in heterothallic species such as $P$. parasitica. However, it has been demonstrated that homothallic mating can be induced by the action of mating hormone produced by an opposite mating type (Ko, 1988). Sexual reproduction will result in the formation of oospores. Infection by Phytophthora occurs through the release from sporangia of motile, biflagellate zoospores, which are chemotactically attracted to the leaves or roots of potential host plants. Upon contact of the plant surface, the zoospores encyst rapidly and germinate. The germ tubes then swell to form appressoria or appressorium-like structures that facilitate adhesion and penetration of the plant surface. Following penetration, coenocytic mycelia grow and become colonized on the host. The infection cycle is completed with the formation of sporangia which usually occurs within a few days of initial invasion (Hardham, 2001; Judelson and Blanco, 2005). Despite of their importance in the process of disease development, mechanisms underlying differentiation of sporangia and zoospores, as well as pathogenesis of 
Phytophthora spp. have been chronically understudied at the molecular level. Tremendous progress has been made recently, however, with the completion of genome and EST (expressed sequence tag) sequencing projects for the potato and tomato late blight pathogen $P$. infestans, the sudden oak death pathogen $P$. ramorum, and the soybean root rot pathogen $P$. sojae (Kamoun and Smart, 2005; Randall et al., 2005). Availability of genome sequences now provides unique opportunity for data mining and unraveling of complex molecular mechanisms which underlie the infection by Phytophthora. In this context, in addition to tools required for functional genomics such as DNA transformation, there is increasing need for well-defined methods for analysis of gene expression, which promises to provide insight into the complex regulatory network and helps to identify genes involved in specific biological processes.

Common methods for RNA quantification include Northern blotting, RNase protection analysis, microarray, and qRT-PCR. No matter which method is used, normalization with an internal control gene, usually a housekeeping gene such as ACT or glyceraldehyde-3-phosphate dehydrogenase (GAPDH), is required in order to correct the sample-to-sample variation which might arise in the process of RNA quantification experiments (Bustin, 2002). Although it is usually assumed that, regardless of experimental conditions, the expression of housekeeping genes is kept constant, it can indeed vary considerably across different developmental stages and thereby leads to dramatic misinterpretation of the expression profile of a target gene (Lee et al., 2002; Steele et al., 2002). It is thus important to identify housekeeping genes which are expressed with constant levels regardless of life stages and determine the optimal number of internal control genes required for accurate data normalization. In this study, the expression of 18 genes at different life stages of $P$. parasitica were analyzed by qRT-PCR and evaluated for their potential as a suitable internal control for study of gene expression in this pathogen.

\section{Materials and methods}

\subsection{Phytophthora parasitica strains and growth conditions}

Phytophthora parasitica strains 98151 (mating type A2), 98130_1 (mating type A1), and 98130_2 (mating type A2) were provided by Dr. P.J. Ann (Taiwan Agricultural Research Institute, Wu Fong, Taiwan), and stored on sterile distilled water as described by Liou et al. (2002). For preparation of zoospores, cysts, germinated cysts, and sporangia, agar blocks of isolate 98130_2, which was grown on 5\% V8 juice agar plate (5\% Campbell's V8 juice, $0.02 \% \mathrm{CaCO}_{3}$, and $2 \%$ agar) at $25^{\circ} \mathrm{C}$ in the dark for 12 days, were soaked in $30 \mathrm{~mL}$ of sterile distill water and incubated at $25^{\circ} \mathrm{C}$ for 2 days under fluorescent light to induce sporangia formation. Afterwards, sporulating hyphae were chilled at $4{ }^{\circ} \mathrm{C}$ for $20 \mathrm{~min}$, followed by incubation at room temperature for additional $5-10 \mathrm{~min}$. The zoospores released from the sporangia were collected by centrifugation at $1000 \mathrm{~g}$. To prepare cysts, the zoospore suspension was agitated with a Vortex mixer (Vortex-Genie 2, Scientific Industries, Bohemia, NY) for 1 min to induce encysting (Ho and Ko, 1997). For preparation of germinated cysts, zoospores were resuspended in $5 \% \mathrm{~V} 8$ juice medium (5\% Campbell's V8 juice and $\left.0.02 \% \mathrm{CaCO}_{3}\right)$, and incubated at $25^{\circ} \mathrm{C}$ in the dark for $4 \mathrm{~h}$. Sporangia were prepared by digesting the sporulating hyphae with $1 \%$ lysing enzyme (Sigma, Saint Louis, MO) and $0.2 \%$ cellulase (Sigma) for $2-4 \mathrm{~h}$, and filtering through one layer of Miracloth. The sporangia were collected by centrifugation at $1000 \mathrm{~g}$.

For samples representing the sexual stage, $P$. parasitica isolates 98130_1 and 98130_2 were inoculated separately on $5 \% \mathrm{~V} 8$ juice agar plates overlaid with one piece of polycarbonate membrane $(0.2 \mu \mathrm{m}, 90 \mathrm{~mm}$ diam; Nuclepore, Pleasanton, California). After incubation for 4-5 days at $25^{\circ} \mathrm{C}$ in the dark, the inoculum was removed and polycarbonate membrane carrying the mycelium of 98130_1 was peeled off the agar plate, and transferred to agar plates inoculated with 98130_2. The membrane was deposited inside the petri dish either up-side-down to allow direct contact of mycelia from both mating types and thus occurrence of sexual reproduction by heterothallic mating, or right-side-up to avoid direct contact of the mycelia from different mating type. In the latter case, sexual reproduction could still occur via inducible homothallic mating (Ko, 1988). For both heterothallic and induced homothallic mating, antheridia and oogonia usually appeared 3 days after initiation of the mating experiments. At the end of each experiment, mycelia collected from the polycarbonate membrane were frozen instantly in liquid nitrogen and stored at $-80^{\circ} \mathrm{C}$ until use.

\subsection{Inoculation experiments}

Inoculation experiments were performed according to Yan and Liou (2005) with some modifications. Detached leaves obtained from the third- to fourth-leaf stage of tomato seedlings were soaked in a zoospore suspension of $P$. parasitica $\left(10^{6}\right.$ zoospores $\left./ \mathrm{mL}\right)$ for $10 \mathrm{~min}$. After removal of the residual suspension, the inoculated leaves were transferred to a petri dish and incubated at $25^{\circ} \mathrm{C}$ in the dark for the indicated period of time. Control leaves were mockinoculated with distilled water. At the end of each experiment, plant samples were frozen instantly in liquid nitrogen and stored at $-80^{\circ} \mathrm{C}$ until use.

\subsection{Cloning the partial sequences of ACT, glucose-6- phosphate dehydrogenase (G6PDH), hypoxanthine guanine phosphoribosyltransferase (HGPRT), phospholipase A2 (PLA2), and TATA box binding protein (TBP)}

Sequences of the housekeeping genes (Table 1) were obtained from GenBank of NCBI (http://www.ncbi.nlm. nih.gov/), with the exception of ACT, HGPRT, PLA2, G6PDH, and TBP, which were unavailable from the public database and thus were cloned and analyzed in this study. 
Table 1

Housekeeping genes evaluated in this study and sequences of primers for qRT-PCR

\begin{tabular}{|c|c|c|c|c|}
\hline Name of genes & Accession No. & Primer & Sequences & Size $(b p)$ \\
\hline $\operatorname{ACT}(\beta$-actin $)$ & DQ227744 & $\begin{array}{l}\text { Act_F1 } \\
\text { Act_R1 }\end{array}$ & $\begin{array}{l}\text { ACTCTGGTGATGGTGT } \\
\text { CGAGTAACCACGCTCC }\end{array}$ & 137 \\
\hline GAPDH (glyceraldehyde-3-phosphate dehydrogenase) & CK859486 & $\begin{array}{l}\text { G3PD_F1 } \\
\text { G3PD_R1 }\end{array}$ & $\begin{array}{l}\text { GGGAGTGAACCACAAGGAGT } \\
\text { GTTGTCGTTGATCACCTTGG }\end{array}$ & 103 \\
\hline G6PDH (glucose-6-phosphate dehydrogenase) & DQ227746 & $\begin{array}{l}\text { G6PDH_F1 } \\
\text { G6PDH_R1 }\end{array}$ & $\begin{array}{l}\text { GACGTACTGCGTGGCAAG } \\
\text { TCACCTTCTGCGTCTCAATC }\end{array}$ & 106 \\
\hline HGPRT (hypoxanthine-guanine phosphoribosyltransferase) & DQ227743 & $\begin{array}{l}\text { HGPRT_F1 } \\
\text { HGPRT_R1 }\end{array}$ & $\begin{array}{l}\text { TTCGTAGCTCTTGACTCGGA } \\
\text { CTTCTTCCACGCTCTCGTC }\end{array}$ & 103 \\
\hline OPEL (secretory protein) & AY251668 & $\begin{array}{l}\text { OPEL_F1 } \\
\text { OPEL_R1 }\end{array}$ & $\begin{array}{l}\text { TCGTACGACTCGAACACGAT } \\
\text { TCCGTCTGAGAGAAGTCGAA }\end{array}$ & 101 \\
\hline PLA2 (phospholipase A2) & DQ227745 & $\begin{array}{l}\text { PLA2_F1 } \\
\text { PLA2_R1 }\end{array}$ & $\begin{array}{l}\text { CTCCGGAAGAAGAACTGGAG } \\
\text { TACTGAGGTCCGTCTTGAGC }\end{array}$ & 126 \\
\hline Ppil (peptidyl prolyl isomerase 1) & CF891681 & $\begin{array}{l}\text { ppil_F1 } \\
\text { ppil_R1 }\end{array}$ & $\begin{array}{l}\text { GAGAAGTTCCCGGATGAGAA } \\
\text { ACCGTGCAGATGAAGAACTG }\end{array}$ & 110 \\
\hline Ppi2 (peptidyl prolyl isomerase 2) & CF891689 & $\begin{array}{l}\text { ppi2_F1 } \\
\text { ppi2_R1 }\end{array}$ & $\begin{array}{l}\text { GGTCGTCGTCACTGAAAGC } \\
\text { CACGCCAAGTATCCGACATA }\end{array}$ & 107 \\
\hline RL13 (60S ribosomal protein L13) & CK859446 & $\begin{array}{l}\text { RL13_F1 } \\
\text { RL13_R1 }\end{array}$ & $\begin{array}{l}\text { AGGCTCTGAGCATCGGTATT } \\
\text { GTTCTTGGGCTTGTTGCTCT }\end{array}$ & 140 \\
\hline TBP (TATA box binding protein) & DQ227742 & $\begin{array}{l}\text { TBP_F1 } \\
\text { TBP_R1 }\end{array}$ & $\begin{array}{l}\text { AAGATGACAGCACCACCATC } \\
\text { CGTTGGTCTTAGACGTTAGCC }\end{array}$ & 101 \\
\hline eEF1A (translation elongation factor $1 \alpha$ ) & AY 564137 & $\begin{array}{l}\text { TEF1_F1 } \\
\text { TEF1_R1 }\end{array}$ & $\begin{array}{l}\text { CTGAAGTCAAGTCCGTCGAG } \\
\text { GTGGTTCAGCACAATCACCT }\end{array}$ & 187 \\
\hline eEF2 (translation elongation factor 2) & CF891679 & $\begin{array}{l}\text { TEF2_F1 } \\
\text { TEF2_R1 }\end{array}$ & $\begin{array}{l}\text { GACCGTTTCTACGACCGTCT } \\
\text { CAGAAGGCCGAAACAAATCT }\end{array}$ & 118 \\
\hline eEF3 (translation elongation factor 3) & CK859418 & $\begin{array}{l}\text { TEF3_F1 } \\
\text { TEF3_R1 }\end{array}$ & $\begin{array}{l}\text { CCGTCGATCAACAACATCTC } \\
\text { GTCAGCATCTTGATCAGCGT }\end{array}$ & 101 \\
\hline Tub-a ( $\alpha$-tubulin) & CK859494 & $\begin{array}{l}\text { a-tub_F1 } \\
\text { a-tub_R1 }\end{array}$ & $\begin{array}{l}\text { CCTAGCGAAGTATGGGATGC } \\
\text { AACTTTGGCACCAATTGTCA }\end{array}$ & 113 \\
\hline Tub-b ( $\beta$-tubulin) & AY 564081 & $\begin{array}{l}\text { b-tub_F1 } \\
\text { b-tub_R1 }\end{array}$ & $\begin{array}{l}\text { AGGAGATGTTCAAGCGTGTG } \\
\text { GATCGTTCATGTTGGACTCG }\end{array}$ & 129 \\
\hline Ubc (ubiquitin-conjugating enzyme) & CK859493 & $\begin{array}{l}\text { ubc_F1 } \\
\text { ubc_R1 }\end{array}$ & $\begin{array}{l}\text { CCACTTAGAGCACGCTAGGA } \\
\text { TACCGACTGTCCTTCGTTCA }\end{array}$ & 152 \\
\hline WS21 (40S ribosomal protein S3A) & CF891675 & $\begin{array}{l}\text { WS21_F1 } \\
\text { WS21_R1 }\end{array}$ & $\begin{array}{l}\text { CTCCAGAACGTGTACATCCG } \\
\text { TAGCGCCCTTCTCCTCAG }\end{array}$ & 106 \\
\hline WS41 (protein of the BAR-domain family) & CF891677 & $\begin{array}{l}\text { WS41_F1 } \\
\text { WS41_R1 }\end{array}$ & $\begin{array}{l}\text { TTCAAGTCCAGTGAGATCGG } \\
\text { TTGTGTCTTTGTGTGATGCG }\end{array}$ & 128 \\
\hline
\end{tabular}

To clone these genes by PCR using genomic DNA as the template, homologues retrieved from the genome databases of $P$. sojae and $P$. ramorum (http://www.jgi.doe.gov/) were used as a reference to design primers: 5'-GAC GCC CCG CGT GCC GTG TT- $3^{\prime}$ and $5^{\prime}-\mathrm{CAG}$ CTT CTC CTT GAT GTC CC-3' for ACT, 5'-GTG CTC AAG GGC GGC AGC GC-3' and 5'-AAG TCG GCC TGG AAG CCG-3' for HGPRT, $5^{\prime}$-GAC GTG ATG CAG AA CCA-3' and 5'-CTC GTC GCT CTC CTT GG-3' for G6PDH, 5' -CCG TGC GAG CCC TTC AC-3' and 5'-GCA GTT GGC CTT GGG CAT-3' for PLA2, and 5'-GAC CCC AAG ACG ACG GC-3' and 5'-GAA CAG CTC CGG CTC GTA-3' for TBP. In addition, 3' RACE was performed as described by Yan and Liou (2005) to obtain 3'-untranslated regions of PLA2, TBP, and WS41, using the following primers: 5'-TTT ACC GCC AAT GGA TGC GGC ACG3' for PLA2; 5'-TGA CAT CCG CTT CCC GAT TCG TCT-3' for TBP, and 5'-TTC AAG TCC AGT GAG ATC GG-3' for WS41. Nucleotide sequences of the recombinant clones were determined on both strands of DNA using the BigDye terminator cycle sequencing ready reaction kit and an ABI Prism 310 Genetic Analyzer apparatus (Applied Biosystems, Foster City, CA). Sequences were analyzed using programs in the GCG software package (Genetics Computer Group, Wisconsin Package Version 10.0).

\section{4. $q R T-P C R$ analysis}

Total RNA was isolated using the TriZol reagent (Invitrogen, Carlsbad, CA), followed by treatment with 
RNase-free DNase I ( $0.5 \mathrm{U} / \mu \mathrm{L}$; Roche, Mannheim, Germany) at $37^{\circ} \mathrm{C}$ for $1 \mathrm{~h}$ to remove the genomic DNA. The concentration of RNA was determined by spectrophotometry, using GeneQuant II (Amersham Biosciences, Uppsala, Sweden). Reverse transcription was performed with PowerScript ${ }^{\mathrm{TM}}$ reverse transcriptase (Clontech, Palo Alto, CA) in a $20-\mu \mathrm{L}$ reaction, using $1 \mu \mathrm{g}$ of total RNA as the template and $5^{\prime}-\mathrm{T}_{25} \mathrm{VN}-3^{\prime}$ (V: A, C, or G; N: A, T, C, or G) as the primer. After $10 \times$ dilution with $\mathrm{ddH}_{2} \mathrm{O}, 1 \mu \mathrm{L}$ of the diluted reverse transcription mixture was submitted in triplicate to quantitative PCR with the LightCycler system using FastStart DNA Master SYBR Green I kit (Roche). The PCR was performed in a volume of $20 \mu \mathrm{L}$ containing $2 \mu \mathrm{L}$ of LightCycler FastStart DNA Master SYBR Green I, $3 \mathrm{mM} \mathrm{MgCl}_{2}$, and $1 \mu \mathrm{M}$ of primers. The instrument settings were: initial enzyme activation at $95^{\circ} \mathrm{C}$ for $10 \mathrm{~min}$, followed by 40 cycles of $95^{\circ} \mathrm{C} / 10 \mathrm{~s}, 60^{\circ} \mathrm{C} / 5 \mathrm{~s}$, and $72^{\circ} \mathrm{C} / 10 \mathrm{~s}$. Oligonucleotide primers for quantitative PCR (Table 1) were designed based on the sequences of each gene using an on-line design tool: https://www.genscript.com/ssl-bin/app/primer. Analysis for the expression of the pppgl gene, which is known to encode an endopolygalacturonase in $P$. parasitica, was performed according to Yan and Liou (2005). All the experiments were performed with RNA from two different sets of samples.

\subsection{Statistical analysis}

The results obtained from qRT-PCR were analyzed using the geNorm program (http://medgen.ugent.be/ jvdesomp/genorm) for calculation of the gene expression stability ( $M$ ); genes with the lowest $M$ value are the most stably expressed (Vandesompele et al., 2002). Furthermore, to estimate the optimal number of internal control genes required for reliable normalization, normalization factors $\left(\mathrm{NF}_{n}\right)$ were calculated by stepwise inclusion of the most stably expressed housekeeping genes. Subsequently, pairwise variations $\left(\mathrm{V}_{n / n+1}\right)$ were calculated for every series of $\mathrm{NF}_{n}$ and $\mathrm{NF}_{n+1}$ to determine the effect of adding a $(n+1)$ th gene. A great variation indicated that the newly added gene has a significant effect on normalization and thus should preferably be included for calculation of a reliable normalization factor (Vandesompele et al., 2002).

The expression profile of the pppgl gene was analyzed and tested for significance by a randomisation test implemented in the relative expression software tool $\left(\mathrm{REST}^{\odot}\right)$ (http://www.gene-quantification.info), which is an Excelbased application for the groupwise comparison and statistical analysis of relative expression results in qRT-PCR (Pfaffl et al., 2002).

\section{Results}

\subsection{Selection of housekeeping genes and specificity of the primer sets}

A total of 18 housekeeping genes known to be involved in different aspects of cellular functions were evaluated for

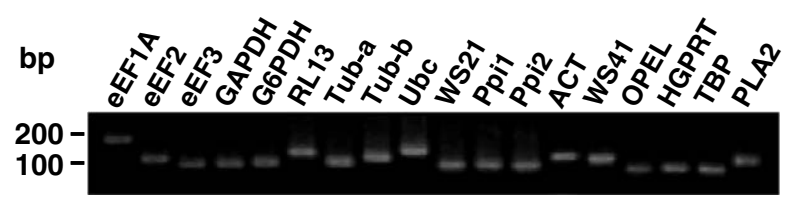

Fig. 1. Analysis of the amplified products obtained from qRT-PCR by $3 \%$ agarose gel electrophoresis. Name of each housekeeping gene was shown on top of the gel.

their potential as good internal controls, including ACT, GAPDH, G6PDH, HGPRT, OPEL (an abundant secretory protein), peptidyl prolyl isomerase 1 (Ppi1), peptidyl prolyl isomerase 2 (Ppi2), PLA2, ribosomal protein L13a (RL13), TBP, eEF1A, translation elongation factor 2 (eEF2), translation elongation factor 3 (eEF3), $\alpha$-tubulin (Tub-a), Tub-b, Ubc, WS21 (40S ribosomal protein S3A), and WS41 (protein of the BAR-domain family). Of these genes, Phytophthora sequences of ACT, G6PDH, PLA2, HGPRT, and TBP were not available from the public database, and thus were cloned and analyzed in the present study. The resultant sequence data have been deposited in the GenBank database under Accession Nos. DQ227742, DQ227743, DQ227744, DQ227745, and DQ227746 (Table 1).

Primers for qRT-PCR were designed based on sequences corresponding to the $3^{\prime}$ portion of each gene, in order to alleviate problems which might be caused by RNA turnover and inefficient reverse transcription (Table 1). Specificity of each primer set was examined by qRT-PCR using RNA prepared from mycelia as the starting material. Amplification of a specific transcript was confirmed by the appearance of a single peak in the melting curve analysis following completion of the amplification reaction (data not shown). Besides, the amplified products were further analyzed by agarose gel electrophoresis and ethidium bromide staining. Only a single band with the expected size (Table 1) was detected in each experiment (Fig. 1), indicating good specificity of all the primer sets in qRT-PCR.

\subsection{The expression profile and expression stability of the housekeeping genes}

To analyze the transcription level of each gene in different life stages of $P$. parasitica, total RNA was isolated from a variety of samples, corresponding to the asexual stage (non-sporulating mycelia, sporangia, zoospores, cysts, and germinated cysts), the sexual stage (heterothallic mating mycelia and induced homothallic mating mycelia), and infection of tomato leaves (Table 2), respectively, and analyzed by qRT-PCR. Transcription profiles of the 18 genes for every individual RNA sample were shown in Fig. 2. $C_{\mathrm{p}}$ (cross point) value is defined as the number of cycles needed for the amplification signal to reach a specific threshold level of detection, and thus is correlated inversely with the amount of cDNA template present in the PCR amplification reaction (Rasmussen, 2001). As shown in Fig. 2, $C_{\mathrm{p}}$ values for 
Table 2

Description of Phytophthora parasitica RNA samples analyzed in this study

\begin{tabular}{|c|c|c|c|}
\hline Stage & Sample & P. parasitica strain & Description of sample used for RNA isolation \\
\hline \multicolumn{4}{|c|}{ Asexual } \\
\hline & MyA1 & 98130_1(A1) & Mycelia, non-sporulating growth \\
\hline & MyA2 & 98130_2(A2) & Mycelia, non-sporulating growth \\
\hline & Zo & 98130_2(A2) & Zoospores, purified \\
\hline & $\mathrm{Cy}$ & 98130_2(A2) & Cysts, purified \\
\hline & Cyg & 98130_2(A2) & Germinated cysts with non-branched hyphae \\
\hline & $\mathrm{Sp}$ & 98130_2(A2) & Sporangia, purified \\
\hline \multicolumn{4}{|l|}{ Sexual } \\
\hline & Hetm-1 & 98130_1 (A1) and 98130_2 (A2) & Three days after initiation of heterothallic mating \\
\hline & Hetm-2 & 98130_1 (A1) and 98130_2 (A2) & Three days after initiation of heterothallic mating \\
\hline & Ihom-1 & 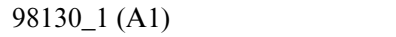 & One day after initiation of induced homothallic mating \\
\hline & Ihom-2 & 98130_1(A1) & Two days after initiation of induced homothallic mating \\
\hline & Ihom-3 & 98130_1 (A1) & Three days after initiation of induced homothallic mating \\
\hline \multicolumn{4}{|c|}{ Pathogenesis } \\
\hline & Tom-1 & $98151(\mathrm{~A} 2)$ & Tomato leaves one day post-inoculation \\
\hline & Tom-2 & $98151(\mathrm{~A} 2)$ & Tomato leaves two days post-inoculation \\
\hline & Tom-3 & $98151(\mathrm{~A} 2)$ & Tomato leaves three days post-inoculation \\
\hline
\end{tabular}

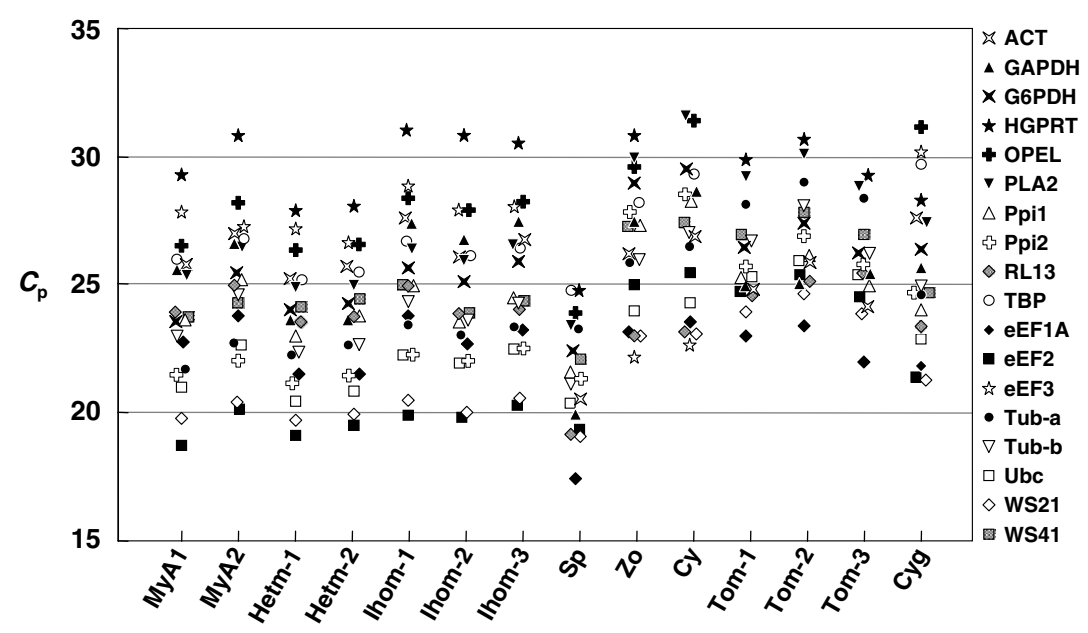

Fig. 2. The transcription profile of each housekeeping gene in absolute $C_{\mathrm{p}}$ values over all RNA samples.

HGPRT obtained from different RNA samples were usually higher than those of other genes, indicating a relatively low level of HGPRT transcription in most life stages of $P$. parasitica. Moreover, the expression of HGPRT was barely detectable in the cysts. Genes encoding translation elongation factors, in contrast, were found to display relatively low $C_{\mathrm{p}}$ values, with eEF1A being the most highly expressed in sporangia and inoculated tomato leaves, eEF2 in non-sporulating mycelia and the sexual stage, while eEF3 in zoospores and cysts. However, the expression of eEF3 and TBP was undetectable in inoculated tomato leaves, very likely due to interference caused by non-specific amplification of tomato cDNA primed by eEF3 and TBP primers.

To identify genes expressed constantly at different life stages of $P$. parasitica, the gene expression stability $(M)$ of each housekeeping gene was calculated by using the geNorm program (Vandesompele et al., 2002). This value reflects the stability of gene transcription levels across different RNA samples; a gene with the lowest $M$ value has the most stable expression. The rank of the housekeeping genes based on their $M$ values was shown in Table 3. When RNAs from all 14 samples were taken into account, designated as 'all stages,' the expression of Ubc and WS21 was found to be the most stable, with an $M$ value of 0.44 , followed by Tub-b, WS41, PLA2, and other genes as shown in Table 3. The rank of Ubc and WS21 could not be discriminated since the gene expression stability was calculated based on the gene expression ratio. The expression of ACT, in contrast, was found to vary from stage to stage as reflected by its high $M$ value of 1.57 (data not shown).

To identify genes expressed constantly at specific life stages of $P$. parasitica, such as the asexual stage, sexual reproduction, and pathogenesis, analysis by the geNorm program was performed with subsets of RNA samples, and the gene expression stability of each gene was recalculated. The rank of the housekeeping genes based on their gene expression stability in different subsets of RNA samples was shown in Table 3. For the asexual stage, which 
Table 3

Rank of housekeeping genes (HKGs) based on their gene expression stability $M^{\text {a }}$

\begin{tabular}{|c|c|c|c|c|c|c|c|}
\hline \multicolumn{2}{|l|}{ All stages ${ }^{b}$} & \multicolumn{2}{|l|}{ Asexual stage $^{\mathrm{b}}$} & \multicolumn{2}{|c|}{$\underline{\text { Sexual reproduction }}^{\mathrm{b}}$} & \multicolumn{2}{|l|}{ Pathogenesis $^{\mathrm{b}}$} \\
\hline HKGs & $M$ & HKGs & $M$ & HKGs & $M$ & HKGs & $M$ \\
\hline Ubc and WS $21^{\mathrm{c}}$ & 0.44 & $\mathrm{Ubc}$ and $\mathrm{WS} 21^{\mathrm{c}}$ & 0.45 & Ubc and Tub- $b^{c}$ & 0.16 & $\mathrm{Ubc}$ and $\mathrm{WS} 21^{\mathrm{c}}$ & 0.15 \\
\hline Tub-b & 0.54 & WS41 & 0.59 & PLA2 & 0.20 & WS41 & 0.32 \\
\hline WS41 & 0.61 & Tub-b & 0.64 & OPEL & 0.23 & PLA2 & 0.38 \\
\hline PLA2 & 0.73 & Ppil & 0.76 & TBP & 0.28 & Tub-b & 0.42 \\
\hline eEF2 & 0.85 & G6PD & 0.86 & $\mathrm{ACT}$ & 0.31 & Ppi2 & 0.49 \\
\hline Ppi2 & 0.92 & PLA2 & 0.92 & G6PD & 0.35 & G6PD & 0.62 \\
\hline G6PD & 0.98 & eEF2 & 1.00 & Ppi2 & 0.37 & Ppil & 0.72 \\
\hline Ppil & 1.02 & Tub-a & 1.07 & $\mathrm{eEF} 2$ & 0.39 & $\mathrm{eEF} 2$ & 0.82 \\
\hline Tub-a & 1.08 & Ppi2 & 1.13 & WS21 & 0.40 & RL13 & 0.94 \\
\hline eEF1A & 1.24 & TBP & 1.20 & Ppil & 0.42 & HGPRT & 1.03 \\
\hline
\end{tabular}

a Only genes ranked at top 10 were listed.

b RNA samples included in each analysis: MyA1, MyA2, Sp, Zo, Cy, Cyg, Hem-1, Hem-2, Ihom-1, Ihom-2, Ihom-3, Tom-1, Tom-2, and Tom-3 for 'all stages,' MyA1, MyA2, Sp, Zo, Cy, and Cyg for 'asexual stage,' MyA1, MyA2, Hem-1, Hem-2, Ihom-1, Ihom-2, and Ihom-3 for 'sexual reproduction,' MyA1, Cyg, Tom-1, Tom-2, and Tom-3 for 'pathogenesis.'

c The gene expression stability can not be discriminated between the two most stable genes since the $M$ value was calculated based on gene expression ratio (Vandesompele et al., 2002).

included RNAs isolated from non-sporulating mycelia, sporangia, zoospores, cysts, and germinated cysts, the expression of Ubc and WS21 was the most constant, followed by WS41 and Tub-b. For sexual reproduction, which included RNAs prepared from non-sporulating mycelia and those undergoing sexual reproduction initiated by either heterothallic mating (Hetm-1 and Hetm-2) or induced homothallic mating (Ihom-1, Ihom-2, and Ihom-3), the expression of Ubc and Tub-b was the most stable, followed by PLA2 and OPEL. Finally, for pathogenesis, which included RNAs isolated from non-sporulating mycelia, germinated cysts, and tomato leaves inoculated with zoospores of $P$. parasitica (Tom-1, Tom2 , and Tom-3), the expression of Ubc and WS21 was the most stable, followed by WS41 and PLA2. Interestingly, although commonly used as internal controls for study of gene expression in Phytophthora spp., the rank of ACT and eEF1A was pretty low compared to other housekeeping genes evaluated in this study (data not shown).

\subsection{Optimal number of internal control genes for normalization}

Although only one single gene was used as an internal control for data normalization in most studies, it has been suggested that use of more than one gene might generate more reliable results (Tricarico et al., 2002; Vandesompele et al., 2002). To find out the minimal number of internal control genes required for reliable normalization, the pairwise variation $\left(V_{n / n+1}\right)$ was calculated between two sequential normalization factors $\left(\mathrm{NF}_{n}\right.$ and $\left.\mathrm{NF}_{n+1}\right)$ using the geNorm program. A cut-off threshold was set at $V=0.15$, below which the inclusion of an additional control gene is not required (Vandesompele et al., 2002). As shown in Fig. 3, $V_{3 / 4}$ for the pool of both 'all stages' and 'asexual stage' was 0.15 , while inclusion of the fifth internal control gene would result in an increase in the pairwise variation $\left(V_{4 / 5}\right)$, indicating the use of the three most stably expressed genes was good enough for reliable data normalization. In

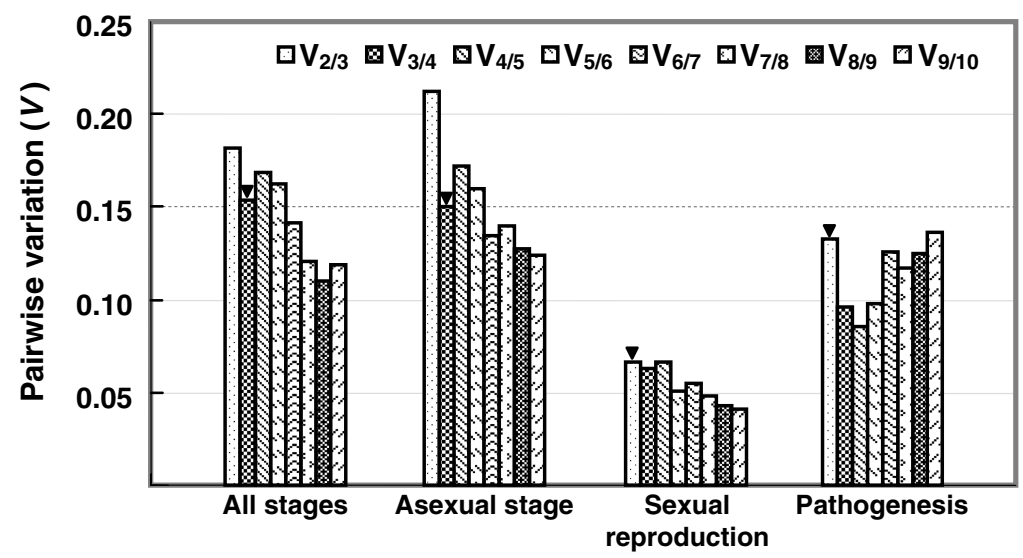

Fig. 3. Pairwise variation $\left(V_{n / n+1}\right)$ analysis between normalization factors $\mathrm{NF}_{n}$ and $\mathrm{NF}_{n+1}$ to determine the optimal number of internal control genes required for reliable normalization. RNA samples included: MyA1, MyA2, Sp, Zo, Cy, Cyg, Hem-1, Hem-2, Ihom-1, Ihom-2, Ihom-3, Tom-1, Tom-2, and Tom-3 for 'all stages,' MyA1, MyA2, Sp, Zo, Cy, and Cyg for 'asexual stage,' MyA1, MyA2, Hem-1, Hem-2, Ihom-1, Ihom-2, and Ihom-3 for 'sexual reproduction,' while MyA1, Cyg, Tom-1, Tom-2, and Tom-3 for 'pathogenesis.' Arrows indicated the optimal numbers of control genes for normalization. 
contrast, $\mathrm{V}_{2 / 3}$ for the pool of 'sexual reproduction' and 'pathogenesis' equaled to 0.07 and 0.13 , respectively, both of which were below the cut-off threshold of 0.15 . Therefore, use of the two most stably expressed genes, namely Ubc and Tub-b for 'sexual reproduction' while Ubc and WS21 for 'pathogenesis,' as internal controls would suffice for reliable data normalization in each case.

\subsection{Analysis of the pppgl expression upon infection of tomato by P. parasitica}

To verify the importance of accurate normalization, RNA was prepared from tomato leaves inoculated with zoospore suspension of $P$. parasitica and subjected to qRTPCR for analysis of pppgl, Ubc, WS21, and ACT. Data obtained for pppgl were then normalized with both Ubc and WS21, as suggested by the aforementioned results, or ACT (Table 4). As shown in Fig. 4A, with both Ubc and WS21 as the internal controls, the expression of pppgl upon infection of tomato was found to be induced one day after zoospore inoculation (1.9-fold, with $P<0.05$ ), enhanced to an even higher level at 2 dpi (11-fold, with $P<0.05)$, and dropped slightly at $3 \mathrm{dpi}$ (9.2-fold, with $P<0.05)$, compared to the pppg1 expression level obtained from germinated cysts. Here, the expression in germinated cysts was used as a reference since penetration of host would presumably occur following germination of cysts. Similar results were obtained while normalization was performed using Ubc or WS21 as the sole internal control (Table 4). In contrast, while normalization was performed using ACT as the internal control, the expression of pppgl upon infection of tomato was found to be repressed compared to that obtained from germinated cysts (Fig. 4B). It is thus obvious

Table 4

A pairwise fixed reallocation randomization test (2000 randomizations) of the relative expression of pppg1 during infection of tomato by Phytophthora parasitica ${ }^{\text {a }}$

\begin{tabular}{llrrr}
\hline Internal control & Parameter & \multicolumn{3}{l}{ RNA sample } \\
\cline { 2 - 4 } & & Tom-1 & Tom-2 & Tom-3 \\
\hline Ubc and WS21 & Relative expression ratio & 1.900 & 11.048 & 9.165 \\
& Standard error & \pm 0.240 & \pm 2.210 & \pm 1.057 \\
& $P$ value & 0.001 & 0.001 & 0.001 \\
Ubc & Relative expression ratio & 2.174 & 10.654 & 8.790 \\
& Standard error & \pm 0.275 & \pm 2.132 & \pm 1.014 \\
& $P$ value & 0.001 & 0.001 & 0.001 \\
WS21 & Relative expression ratio & 1.660 & 11.456 & 9.557 \\
& Standard error & \pm 1.069 & \pm 7.562 & \pm 6.115 \\
& $P$ value & 0.001 & 0.001 & 0.001 \\
ACT & Relative expression ratio & 0.026 & 0.138 & 0.034 \\
& Standard error & \pm 0.006 & \pm 0.015 & \pm 0.001 \\
& $P$ value & 0.714 & 0.833 & 0.846 \\
\hline
\end{tabular}

\footnotetext{
a The amount of pppgl transcript present in the inoculated tomato leaves was measured by qRT-PCR, normalized with the indicated internal control(s), and compared with those obtained from germinated cysts by the use of the software 'REST ${ }^{\odot}$ ' (Pfaffl et al., 2002). Tom-1, Tom-2, and Tom-3 indicated tomato leaves collected 1, 2, and 3 days, respectively, after inoculation with the zoospore suspension of $P$. parasitica.
}
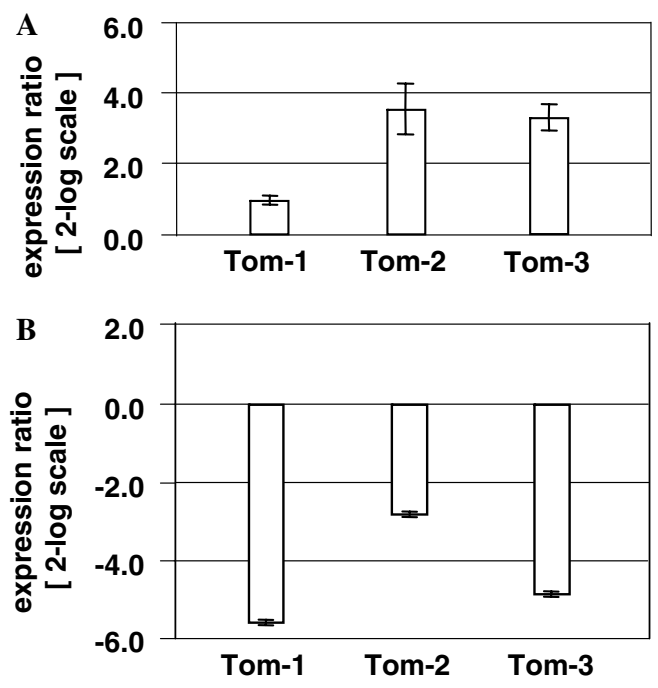

Fig. 4. Quantification of the pppg1 transcript by qRT-PCR. The amount of pppg1 transcript present in the inoculated tomato leaves was measured by qRT-PCR, normalized with the transcript of: (A) Ubc and WS21, or (B) ACT, and compared with those obtained from germinated cysts by the use of the software 'REST ${ }^{\complement}$, (Pfaffl et al., 2002). Results of three experiments were presented as means $\pm \mathrm{SE}$. Tom- 1 , Tom-2, and Tom-3 indicated tomato leaves collected 1,2 , and 3 days, respectively, after inoculation with the zoospore suspension of Phytophthora parasitica.

that normalization with different internal control genes would result in completely different conclusion.

\section{Discussions}

qRT-PCR has become one of the most commonly used methods for study of gene expression in recent years. Compared with conventional methods for direct detection of mRNA such as Northern hybridization and RNase protection analysis, qRT-PCR has the advantages of sensitivity, large dynamic range, and high sample throughput. Nonetheless, as has been noticed for other methods, accurate normalization with a right internal control is required to remove sampling difference in regard to RNA quantity and quality to identify the real gene-specific variation (Bustin, 2002). Ideally, a control gene should be constantly transcribed regardless of developmental stages and experimental conditions. In this regard, what was known about Phytophthora spp. has been very scanty, if there was any, despite that selection of suitable housekeeping genes has been well documented for other organisms (Nicot et al., 2005; Nielsen and Boye, 2005; Radonić et al., 2004).

To identify housekeeping genes suitable for internal control, the expression of 18 housekeeping genes at different life stages of $P$. parasitica was analyzed by qRT-PCR, followed by evaluation using the geNorm program (Vandesompele et al., 2002). By pairwise comparison, this method ranked the test genes according to the similarity of their expression profile so that genes with the most stable expression level in a given set of RNA samples could be identified (Nicot et al., 2005; Nielsen and Boye, 2005). In our study, analysis by the geNorm program indicated that the 
expression of ACT, which was commonly used as an internal control for study of gene expression in Phytophthora spp. (Armstrong et al., 2005; Avrova et al., 2003; van West et al., 1998), varied greatly from stage to stage as reflected by its high $M$ value. Similar results have been obtained in other studies (Nicot et al., 2005; Selvey et al., 2001; Steele et al., 2002). Besides, the rank of eEF1A, which was used occasionally as an internal control in P. infestans (Cvitanich and Judelson, 2003; Kim and Judelson, 2003), was pretty low among the housekeeping genes tested. Thus, it appeared that these two genes were not suitable internal controls for data normalization in P. parasitica. In contrast, the expression of Ubc and WS21 was found to show minimal changes in RNA pool representing 'all stages', 'asexual stage,' and 'pathogenesis,' respectively. Ubc is known to encode an ubiquitin-conjugating enzyme, which catalyses the covalent attachment of ubiquitin to target proteins, while WS21 codes for a 40S ribosomal protein (Shan et al., 2004). In addition, Tub-b and WS41 also ranked high among the test genes. Tub-b is the gene coding for $\beta$-tubulin, while WS41 for a protein which contains a putative conserved domain, BAR (SM00721) (Habermann, 2004). In accordance with our results, it has been demonstrated previously that both WS21 and WS41 were constitutively expressed in different developmental stages of $P$. parasitica (Shan et al., 2004). Furthermore, WS41 has been the choice as an internal control for analysis of gene expression by Northern blot (Shan and Hardham, 2004). Analysis using the geNorm software also recommended the use of the three most stable genes for reliable normalization of a target gene within the pool of 'all stages' and 'asexual stage,' while two for the pool of 'sexual reproduction' and 'pathogenesis.'

The importance of using a suitable internal control for data normalization can be envisaged from the analysis of the pppg1 expression. Normalization with the two most stably expressed genes identified for 'pathogenesis,' namely Ubc and WS21, clearly demonstrated that the expression of pppgl was highly induced compared to the pppgl expression level obtained from germinated cysts. Normalization with ACT, the expression of which appeared to vary greatly at different life stages of $P$. parasitica, in contrast, indicated that the expression of pppgl was somehow repressed compared to that obtained from germinated cysts. It is thus obvious that normalization with genes exhibiting variable expression may lead to misinterpretation of the result and even a different conclusion.

According to the geNorm, the minimal number of internal control genes required for reliable normalization would be at least two rather than one, as seen in the case for 'pathogenesis,' since the conclusion was drawn based on pairwise variations of normalization factors. As mentioned in the previous section, the rank of Ubc and WS21 could not be discriminated due to the required use of the gene expression ratio for calculation of the $M$ value. The possibility existed, however, that the transcription profile of Ubc was indeed very similar to that of WS21. In this case, it was likely that normalization with either Ubc or WS21 would show a result similar to that normalized with both genes. To test the hypothesis, the expression of pppgl was normalized with either gene alone. The results indicated that normalization with Ubc or WS21 as the sole internal control generated results which were essentially the same as that normalized with both genes. It was thus suggested that, if the expression of a housekeeping gene was known to be constant across a given set of RNA samples, then use of this single gene as an internal control would be sufficient for reliable normalization, despite that use of more than one has been suggested by other studies (Radonić et al., 2004; Tricarico et al., 2002). For study of gene expression in regard to pathogenesis in P. parasitica, use of either Ubc or WS21 would be sufficient.

In conclusion, normalization of qRT-PCR data with a right internal control is essential to obtain results with biological significance. To fulfill this request, the internal control must be selected with caution. In this study, by systematical analysis of a large group of housekeeping genes, suitable internal controls were identified in regard to specific life stages of $P$. parasitica. Besides, it was demonstrated that normalization with a single well selected gene could generate results comparable to that normalized with two. Most importantly, our strategy for selection of internal control genes and analysis of qRT-PCR data may provide a useful guideline for study of gene expression involving other experimental conditions and other Phytophthora spp. as well.

\section{Acknowledgments}

This research was supported in part by grants from Nation Science Council, Taiwan. We thank Dr. P.J. Ann for providing $P$. parasitica isolates, and the US department of Energy Joint Genome Institute for providing access to sequence database.

\section{References}

Armstrong, M.R., Whisson, S.C., Pritchard, L., Bos, J.I., Venter, E., Avrova, A.O., Rehmany, A.P., et al., 2005. An ancestral oomycete locus contains late blight avirulence gene Avr3a, encoding a protein that is recognized in the host cytoplasm. Proc. Natl. Acad. Sci. USA 102, 7766-7771.

Avrova, A.O., Venter, E., Birch, P.R., Whisson, S.C., 2003. Profiling and quantifying differential gene transcription in Phytophthora infestans prior to and during the early stages of potato infection. Fungal Genet. Biol. 40, 4-14.

Baldauf, S.L., Roger, A.J., Wenk-Siefert, I., Doolittle, W.F., 2000. A kingdom-level phylogeny of eukaryotes based on combined protein data. Science 290, 972-977.

Bustin, S.A., 2002. Quantification of mRNA using real-time revere transcription PCR (RT-PCR): trends and problems. J. Mol. Endocrinol. 29, 23-39.

Cvitanich, C., Judelson, H.S., 2003. A gene expressed during sexual and asexual sporulation in Phytophthora infestans is a member of the Puf family of translational regulators. Eukaryot. Cell 2, 465-473.

Erwin, D.C., Ribeiro, O.K., 1996. Phytophthora Diseases Worldwide. APS Press, the American Phytopathological Society, Minnesota.

Gunderson, J.H., Elwood, H., Ingold, A., Kindle, K., Sogin, M.L., 1987. Phylogenetic relationships between cholorphytes, chrysophytes, and Oomycetes. Proc. Natl. Acad. Sci. USA 84, 5823-5827. 
Habermann, B., 2004. The BAR-domain family of proteins: a case of bending and binding? EMBO Rep. 5, 250-255.

Hardham, A.R., 2001. The cell biology behind Phytophthora pathogenicity. Aust. Plant Pathol. 30, 91-98.

Ho, W.C., Ko, W.H., 1997. A simple method for obtaining single-spore of fungi. Bot. Bull. Acad. Sin. 38, 41-44.

Judelson, H.S., Blanco, F.A., 2005. The spores of Phytophthora: weapons of the plant destroyer. Nat. Rev. Microbiol. 3, 47-58.

Kamoun, S., Smart, C.D., 2005. Late blight of potato and tomato in the genomics era. Plant Dis. 89, 692-699.

Kim, K.S., Judelson, H.S., 2003. Sporangium-specific gene expression in the oomycete phytopathogen Phytophthora infestans. Eukaryot. Cell 2, 1376-1385.

Ko, W.H., 1988. Hormonal heterothallism and homothallism in Phytophthora. Annu. Rev. Phytopathol. 26, 57-73.

Lee, P.D., Sladek, R., Greenwood, C.M., Hudson, T.J., 2002. Control genes and variability: absence of ubiquitous reference transcripts in diverse mammalian expression studies. Genome Res. 12, 292-297.

Liou, R.F., Lee, J.T., Lee, H.C., Ann, P.J., 2002. Analysis of Phytophthora parasitica by retrotransposon-derived DNA fingerprinting. Bot. Bull. Acad. Sin. 43, 21-29.

Nicot, N., Hausman, J.-F., Hoffmann, L., Evers, D., 2005. Housekeeping gene selection for real-time RT-PCR normalization in potato during biotic and abiotic stress. J. Exp. Bot. 56, 2907-2914.

Nielsen, K.K., Boye, M., 2005. Real-time quantitative reverse transcription-PCR analysis of expression stability of Actinobacillus pleuropneumoniae housekeeping genes during in vitro growth under iron-depleted conditions. Appl. Environ. Microbiol. 71, 2949-2954.

Pfaffl, M.W., Horgan, G.W., Dempfle, L., 2002. Relative expression software tool (REST) for group-wise comparison and statistical analysis of relative expression results in real-time PCR. Nucleic Acids Res. 30, e36.

Radonić, A., Thulke, S., Mackay, I.M., Landt, O., Siegert, W., Nitsche, A., 2004. Guideline to reference gene selection for quantitative real-time PCR. Biochem. Biophys. Res. Commun. 313, 852-862.
Randall, T.A., Dwyer, R.A., Huitema, E., Beyer, K., Cvitanich, C., Kelkar, H., Fong, A.M., et al., 2005. Large-scale gene discovery in the oomycete Phytophthora infestans reveals likely components of phytopathogenicity shared with true fungi. Mol. Plant Microb. Interact. 18, 229-243.

Rasmussen, R., 2001. Quantification on the LightCycler. In: Meuer, S., Wittwer, C., Nakagawara, K. (Eds.), Rapid Cycle Real-time PCR, Methods and Applications. Springer, Heidelberg, Germany, pp. 21-34.

Selvey, S., Thompson, E.W., Matthaei, K., Lea, R.A., Irving, M.G., Griffiths, L.R., 2001. Beta-actin-an unsuitable internal control for RT-PCR. Mol. Cell Probes 15, 307-311.

Shan, W., Hardham, A.R., 2004. Construction of a bacterial artificial chromosome library, determination of genome size, and characterization of an Hsp70 gene family in Phytophthora nicotianae. Fungal Genet. Biol. 41, 369-380.

Shan, W., Marshall, J.S., Hardham, A.R., 2004. Gene expression in germinating cysts of Phytophthora nicotianae. Mol. Plant Pathol. 5, 317-330.

Steele, B.K., Meyers, C., Ozbun, M.A., 2002. Variable expression of some "housekeeping" genes during human keratinocyte differentiation. Anal. Biochem. 307, 341-347.

Tricarico, C., Pinzani, P., Bianchi, S., Paglierani, M., Distante, V., Pazzagli, M., Bustin, S.A., Orlando, C., 2002. Quantitative real-time reverse transcription polymerase chain reaction: normalization to rRNA or single housekeeping genes is inappropriate for human tissue biopsies. Anal. Biochem. 309, 293-300.

Vandesompele, J., De Preter, K., Pattyn, F., Poppe, B., Van Roy, N., De Paepe, A., Speleman, F., 2002. Accurate normalization of real-time quantitative RT-PCR data by geometric averaging of multiple internal control genes. Genome Biol. 3. research 0034.1-0034.12.

van West, P., de Jong, A.J., Judelson, H.S., Emons, A.M., Govers, F., 1998. The ipiO gene of Phytophthora infestans is highly expressed in invading hyphae during infection. Fungal Genet. Biol. 23, 126-138.

Yan, H.Z., Liou, R.F., 2005. Cloning and analysis of pppg1, an inducible endopolygalacturonase gene from the Oomycete plant pathogen Phytophthora parasitica. Fungal Genet. Biol. 42, 339-350. 